\title{
Reconstruction of the Nigrostriatal Pathway by Simultaneous Intrastriatal and Intranigral Dopaminergic Transplants
}

\author{
Ivar Mendez, Damaso Sadi, and Murray Hong \\ Neural Transplantation Laboratory, Departments of Surgery (Division of Neurosurgery), and Anatomy and Neurobiology, \\ Dalhousie University, Halifax, Nova Scotia, Canada B3H 4 H7
}

The main strategy in experimental and clinical neural transplantation in Parkinson's disease has been to place fetal nigral grafts not in their ontogenic site (substantia nigra) but in their target area (striatum). The reason for this ectopic placement is the apparent inability of nigral grafts placed in the ventral mesencephalon (VM) of the adult host to grow axons for long distances that are capable of reaching the ipsilateral striatum and thus restoring the nigrostriatal pathway.

The present study demonstrates for the first time that simultaneous dopaminergic transplants (double grafts) placed in the substantia nigra and ipsilateral striatum of rats bearing unilateral 6-hydroxydopamine lesions reconstruct the dopaminergic nigrostriatal pathway in the adult rat brain. Numerous tyrosine hydroxylase-immunoreactive axons were observed arising from the intranigral graft and growing rostrally along the internal capsule and medial forebrain bundle to reinnervate the ipsilat- eral striatum, which also had received a dopaminergic graft. These double grafts achieved not only greater striatal reinnervation than the standard intrastriatal graft but also a faster and more complete rotational recovery to amphetamine challenge 6 weeks after transplantation.

These results suggest strongly that embryonic nigral transplants implanted in the striatum are capable of promoting growth and providing guidance to axons arising from a dopaminergic graft placed homotopically in the VM, resulting in restoration of the dopaminergic nigrostriatal projection. Reconstruction of the nigrostriatal pathway by double grafts may not only achieve substantial striatal reinnervation but may also contribute to the reestablishment of dopaminergic regulation of the nigrostriatal circuitry.

Key words: double grafts; Parkinson's disease; neural transplantation; dopamine; nigrostriatal pathway; fetal transplants
Evidence for survival and growth of fetal dopaminergic grafts in animal models of Parkinson's disease is well documented. Numerous studies have also demonstrated that grafts induce reversal of biochemical and locomotor deficits produced by lesions in the nigrostriatal system. Restoration of the nigrostriatal pathway, however, has not yet been achieved by current grafting strategies.

To date, the main transplant strategy has been to place nigral grafts not in their ontogenic site but in their target area (striatum). The main reason for this ectopic placement is the apparent inability of nigral grafts placed in the ventral mesencephalon (VM) to grow axons over long distances that are capable of reaching their striatal target. This failure may be the result, in part, of lack of guidance cues in the mature host or the presence of inhibitory factors in myelinated pathways (Schnell and Schwab, 1990; Schwab, 1990; Schwab et al., 1993). Although restoration of efferent nigrostriatal connections has been demonstrated by ectopic placement of nigral grafts (Freund et al., 1985; Clarke et al., 1988; Mendez et al., 1991), afferent striatonigral connections seem to be lacking (Doucet et al., 1989). This lack of host-graft connectivity may impair graft regulation by the host. Conversely, in transplant strategies where the graft has been placed in the ontogenic site, such as intrastriatal transplants in the Huntington's model, afferent connections are abundant, whereas the efferent striatonigral limb is lacking (Wictorin et al., 1989a,b).

\footnotetext{
Received May 6, 1996; revised Aug. 27, 1996; accepted Aug. 29, 1996.

We thank Tanya Acorn for assistance with the preparation of this manuscript. Correspondence should be addressed to Dr. Ivar Mendez, Neural Transplantation Laboratory, Tupper Medical Building, 13th Floor, Dalhousie University, Halifax, Nova Scotia, Canada B3H $4 \mathrm{H} 7$.

Copyright (C) 1996 Society for Neuroscience $0270-6474 / 96 / 167216-12 \$ 05.00 / 0$
}

In an attempt to enhance axonal growth from the substantia nigra to the striatum, several strategies have been used. Fetal striatal tissue cell suspensions were implanted along the nigrostriatal pathway to act as "bridges" for the growth of axons from nigral grafts implanted homotopically in the VM (Dunnett et al., 1989). These investigators observed tyrosine hydroxylase (TH)immunoreactive axons extending along the striatal bridge graft and reinnervating the striatum. In a related bridging technique, Zhou and Chiang (1995) injected ibotenic and kainic acid along the nigrostriatal pathway. These experiments demonstrated axonal growth from a homotopically placed graft to the denervated striatum, suggesting that a chemical lesion may promote axonal guidance and growth. In a recent study, bridge grafts of fibroblast growth factor-4-transfected RN-22 schwannoma cells have been used to reconstruct the nigrostriatal pathway in the adult rat. The presence of the bridge graft also led to an increase in the survival of TH-immunoreactive neurons in the intranigral graft (Brecknell et al., 1996).

Xenografts have also been tried in an attempt to escape the inhibitory factors that may prevent axonal growth in the adult CNS. Long-distance axonal growth along the nigrostriatal tract was observed by implantation of human VM cell suspensions along this pathway (Wictorin et al., 1990, 1992). An alternative approach has been the reconstruction of long axonal pathways by placing grafts in the developing CNS. Recently, fetal dopaminergic grafts were implanted into the VM of lesioned neonatal pups at postnatal day 3 (Nikkhah et al., 1995a). THimmunoreactive fibers were observed growing from the graft along the nigrostriatal pathway and reinnervating the ipsilateral striatum. This anatomical reconstruction correlated well 
with behavioral recovery (Nikkhah et al., 1995b). These observations indicate the remarkable ability of developing tissue to promote axonal growth and guidance along the nigrostriatal pathway.

The present study was designed to investigate whether fetal dopaminergic grafts implanted simultaneously in the striatum and nigra of 6-hydroxydopamine (6-OHDA)-lesioned adult rats promote axonal growth along the nigrostriatal pathway. This study demonstrates for the first time that double grafts of VM tissue have shown restoration of the nigrostriatal pathway. A faster and more complete behavioral recovery was also observed in rats receiving simultaneous intranigral and intrastriatal grafts when compared with animals implanted with either an intranigral or an intrastriatal graft alone.

\section{MATERIALS AND METHODS}

Experimental design. Twenty-two female Wistar rats (200-225 gm) with unilateral 6-OHDA lesions were used in the experiments. In the experimental group, six rats received simultaneous intranigral and intrastriatal transplants (double grafts). The remaining 16 rats were divided into four equal groups. The first group received an intrastriatal transplant only. The second group received an intranigral transplant only. The third group received a striatal graft of nondopaminergic tissue (cortex) and a dopaminergic intranigral graft. The last group received a unilateral 6-OHDA lesion only. Each transplanted animal received a total of 800,000 cells per transplant. In the rats that were implanted with double grafts, each of the two sites was injected with 400,000 cells (see below).

Animals and 6-OHDA lesions. Female Wistar rats (Charles River, St. Constant, Quebec, Canada), weighing 200-225 gm, were housed two animals per cage with food and water ad libitum and allowed to acclimatize for $7 \mathrm{~d}$ in the animal care facility before surgery or behavioral testing. All animal procedures were in accordance with the guidelines of the Canadian Council on Animal Care and the University Council on Laboratory Animals. Rats received two stereotactic injections of 6-OHDA into the right ascending mesostriatal dopaminergic pathway under pentobarbital anesthesia at the following coordinates: (1) $2.5 \mu \mathrm{l}$ of 6-OHDA (3.6 $\mu \mathrm{g}$ 6-OHDA $\mathrm{HBr} / \mu \mathrm{l}$ in $0.2 \mathrm{mg} / \mathrm{ml}$ L-ascorbate $0.9 \%$ saline) at anteroposterior (AP): -4.4 , lateral (L): 1.2 , ventral (V): 7.8, toothbar: -2.4 ; and (2) $3 \mu \mathrm{l}$ of 6-OHDA at AP: -4.0 , L: $0.8, \mathrm{~V}: 8.0$, toothbar: +3.4 . The injection rate was $1 \mu \mathrm{l} / \mathrm{min}$, and the cannula was left in place for an additional $5 \mathrm{~min}$ before being retracted slowly. After a 2 week recovery period in the animal care facility, animals were given an amphetamine challenge $(5 \mathrm{mg} / \mathrm{kg}$, i.p.), and their rotational scores were collected during a $90 \mathrm{~min}$ period. Only animals exhibiting a mean ipsilateral rotation score of nine or more full body turns per minute were included in the study.

Microtransplantation. The technique described by Nikkhah et al. (1994c) was used. In brief, single cell suspensions were prepared from ventral mesencephalic or cortical tissue of 14-d-old rat fetuses and injected stereotactically into the host brains of 6-OHDA-lesioned animals. To obtain sufficient working volumes of cell suspensions, 25-30 VMs were dissected in DMEM (Life Technologies, Gaithersburg, MD) on each of two grafting sessions, and the tissue was incubated in $0.1 \%$ trypsin (Worthington, Freehold, NJ)/0.05\% DNase (DN-25; Sigma, St. Louis, MO)/DMEM at $37^{\circ} \mathrm{C}$ for $20 \mathrm{~min}$, and then rinsed four times in $0.05 \%$ DNase/DMEM. Incubated tissue was then dissociated mechanically until a milky, homogenous single cell suspension was achieved. A final cell concentration of $\sim 200,000$ cells $/ \mu$ l was used with viability $>$ $98 \%$, as determined by the trypan blue dye exclusion method. Each rat was implanted with 800,000 cells. In animals implanted with double grafts, the striatum received 400,000 cells, and the substantia nigra also received 400,000 cells. Control rats received a total of 800,000 cells per site. The stereotactic coordinates are presented in Table 1.

Post-transplant behavioral assessment. Transplanted animals were tested for rotational behavior using a computerized video activity monitor system (Videomex, Columbus Instruments, Columbus, OH). Animals were given an amphetamine challenge ( $5 \mathrm{mg} / \mathrm{kg}$, i.p.), and rotation behavioral testing was carried out in 90 min periods every 3 weeks after transplantation. Statistical analysis for between-group and within-group differences was assessed at $p<0.05$ using two-way ANOVA followed by Tukey's post hoc test.

Fluoro-Gold $(F G)$ injections. Six to eight weeks after transplantation, four animals with double grafts $(n=4)$ received a stereotactic injection of the retrograde neuronal tracer FG ( $2 \%$ in $0.09 \%$ saline). FG was injected into the striatum $(0.4 \mu \mathrm{l}$ per injection) using a microcapillary cannula (40-50 $\mu \mathrm{m}$ tip diameter) at the following coordinates: AP, 0.5 and -0.5 ; lateral to midline, -2.0 and -3.5 ; dorsoventral, -6.0 and -4.0 ; toothbar at -3.3 . Ten days after the injections, animals were anesthetized and perfused, and their brains were sectioned in the same manner as described for immunohistochemistry (see below). Both coronal and sagittal sections were mounted and analyzed for FG labeling by using a fluorescence microscope equipped with filters for $365 \mathrm{~nm}$ excitation. Adjacent sections were stained for TH as described below.

Immunohistochemistry. Six to eight weeks after transplantation, rats were anesthetized with an overdose of pentobarbital and perfused transcardially with $100 \mathrm{ml}$ of $0.1 \mathrm{M}$ phosphate buffer followed by $250 \mathrm{ml}$ of $4 \%$ freshly depolymerized paraformaldehyde in $0.1 \mathrm{M}$ phosphate buffer for $15 \mathrm{~min}$. The brains were removed and post-fixed overnight in $4 \%$ paraformaldehyde in $0.1 \mathrm{M}$ phosphate buffer before being stored for $24 \mathrm{hr}$ in PBS containing 30\% sucrose. Coronal and sagittal sections $40 \mu \mathrm{m}$ thick were cut on a freezing microtome and collected serially in $0.1 \mathrm{M}$ phosphate buffer. Sections were processed for TH immunohistochemistry using a primary rabbit anti-TH antiserum $(1: 2500 \mathrm{Pel}$ Freeze) and the ABC-kit (Vector, Dimension Laboratories, Burlingame, CA). Briefly, sections were prewashed in a solution of $10 \%$ methanol and $3 \%$ hydrogen peroxide for 10 min before being blocked in phosphate buffer containing $0.3 \%$ Triton X-100 and 5\% normal swine serum for $1 \mathrm{hr}$. Sections were then incubated in a 1:2500 solution of rabbit polyclonal anti-TH antibody for $16 \mathrm{hr}$. Antibody binding was visualized using a biotinylated swine anti-rabbit immunoglobulin antibody (Dako, Carpinteria, CA) at 1:500 followed by a streptavidinbiotinylated horseradish peroxidase complex kit (Dako). Peroxidase activity was developed using 3.3'-diaminobenzidine chromagen. Sections were washed in $0.1 \mathrm{M}$ phosphate buffer, mounted on gelatinsubbed slides, dehydrated, and mounted in permount.

Table 1. Details of transplantation surgery

\begin{tabular}{|c|c|c|c|c|c|c|}
\hline \multirow[b]{2}{*}{ Group } & \multirow[b]{2}{*}{$n$} & \multicolumn{3}{|c|}{ Coordinates } & \multirow{2}{*}{$\begin{array}{l}\text { Total graft } \\
\text { volume }\end{array}$} & \multirow{2}{*}{$\begin{array}{l}\text { Total number } \\
\text { of cells }\end{array}$} \\
\hline & & AP & $\mathrm{L}$ & $\mathrm{V}$ & & \\
\hline \multirow[t]{2}{*}{ Striatal } & 4 & +1.3 & 2.1 & 5.5 and 4.3 & $6 \mu \mathrm{l}$ & 800,000 \\
\hline & & +0.3 & 3.7 & 5.5 and 4.3 & & \\
\hline \multirow[t]{2}{*}{ Nigral } & 4 & -4.8 & 2.0 & 8.4 and 8.2 & $6 \mu 1$ & 800,000 \\
\hline & & -5.0 & 2.3 & 8.3 and 8.1 & & \\
\hline Double (control) & 4 & \multicolumn{3}{|c|}{ Same coordinates as for striatal and nigral grafts } & $6 \mu 1$ & 800,000 \\
\hline
\end{tabular}

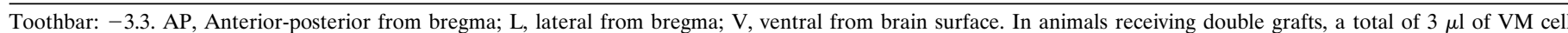

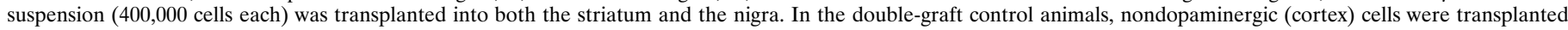
into the striatum, and VM cells were transplanted into the substantia nigra. 
Figure 1. TH-immunostained coronal section of the VM of a rat with a right 6-OHDA lesion of the nigrostriatal pathway. Note the complete absence of THimmunoreactive structures in the substantia nigra (pars compacta and reticulata) and ventral tegmental area. Scale bar, $250 \mu \mathrm{m}$.

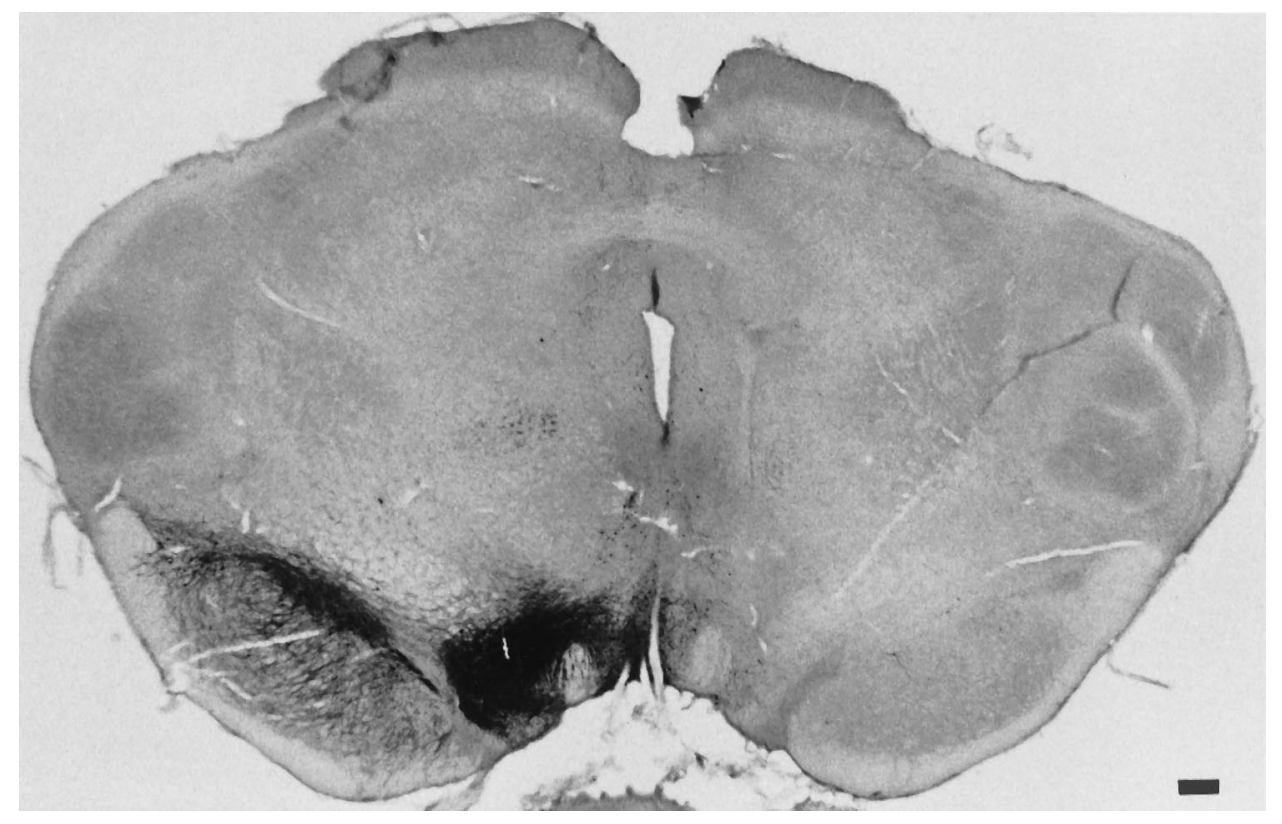

\section{RESULTS}

\section{6-OHDA lesions}

Stereotactic injection of 6-OHDA in the nigrostriatal dopaminergic pathway produced complete disappearance of $\mathrm{TH}$ immunoreactive neurons in the ipsilateral substantia nigra and ventral tegmental area in the lesion-only control group (Fig. 1). No TH-immunoreactive fibers were detected in the medial forebrain bundle (MFB), the internal capsule, or the striatum ipsilateral to the 6-OHDA lesion at 2 or 8 weeks after the lesion.

\section{Single transplants}

\section{Intranigral grafts}

Intranigral grafts were well circumscribed to the VM (Fig. 2). $\mathrm{TH}$-immunoreactive cells tended to cluster in the periphery of the graft, with fewer cells observed in the center of the graft. This arrangement is reminiscent of the normal nigral architecture of a dense cluster of cells (pars compacta) and a less dense area (pars reticulata). In some animals, a few TH-immunoreactive cells were found scattered along the needle tract. $\mathrm{TH}$-immunoreactive fibers extended into the graft itself, creating an extensive network of fibers. Processes also penetrated the host tissue in all directions, but the fiber outgrowth was short and sparse. In some cases, fibers were seen penetrating the cerebral peduncles; however, only a few ascending fibers could be traced growing toward the internal capsule or the MFB. Their trajectory was short, and no fibers could be traced within the internal capsule or the MFB or reaching the striatal complex.

\section{Intrastriatal grafts}

Intrastriatal grafts were formed by dense clusters of $\mathrm{TH}$ immunoreactive perikarya and fibers (Fig. 3). The cells were arranged mainly in the periphery of the graft, where dense clusters of cells were observed. The center of the graft was less populated and contained a few scattered cell bodies. In some cases, a few cells were found scattered along the needle tract in the cortex or corpus callosum. A dense network of TH-positive fibers was observed within the graft itself. Numerous fibers also penetrated the host in all directions, forming a halo of dense TH immunoreactivity around the graft. These fibers could be traced penetrat- ing into the host striatum for variable distances ranging from 500 $\mu \mathrm{m}$ to $2 \mathrm{~mm}$; however, no fibers were encountered entering the internal capsule or the MFB.

\section{Double VM transplants}

Large numbers of TH-immunoreactive neurons were found in clusters in both the intranigral and intrastriatal grafts (Fig. 4). In some cases, the intranigral graft was extensive and covered the VM almost completely. Small clusters of cells were also found along the needle tracts. TH-immunoreactive processes in the intranigral grafts gave rise to a dense network of fibers within the graft and also extended into the host in all directions; however, the only substantial fiber outgrowth occurred in the rostral direction (Fig. 5). Numerous fibers projected rostrally along the MFB medially and the internal capsule laterally. These ascending fibers could be traced from the intranigral graft along the MFB and internal capsule all the way to the striatum (Fig. 6). Fibers traveling along the internal capsule were arranged, in general, in fascicles, whereas along the MFB they were arranged more loosely. A dense network of fibers was also found within the intrastriatal grafts, with processes extending into the surrounding striatum in all directions. In some animals the intrastriatal graft was located along the striatal-pallidal border (Fig. 7). In these cases, numerous fibers could be traced caudally penetrating the pallidum toward the internal capsule or the MFB; however, these fibers could be observed only for distances up to $1.5-2.0 \mathrm{~mm}$, not long enough to reach the substantia nigra.

Qualitatively, the striatal reinnervation in rats receiving double grafts seemed to be more extensive and dense than in animals receiving intrastriatal grafts alone. In some animals with double grafts, TH immunoreactivity was present throughout the entire striatum (Fig. 7). This degree of reinnervation was not apparent in rats receiving intrastriatal grafts alone (Fig. 3).

\section{FG tracing}

The injection of FG resulted in diffuse labeling throughout the striatum, including the intrastriatal graft. Numerous retrogradely labeled cells were also observed in the intranigral graft $10 \mathrm{~d}$ after injection of FG in the ipsilateral striatum of animals that had 

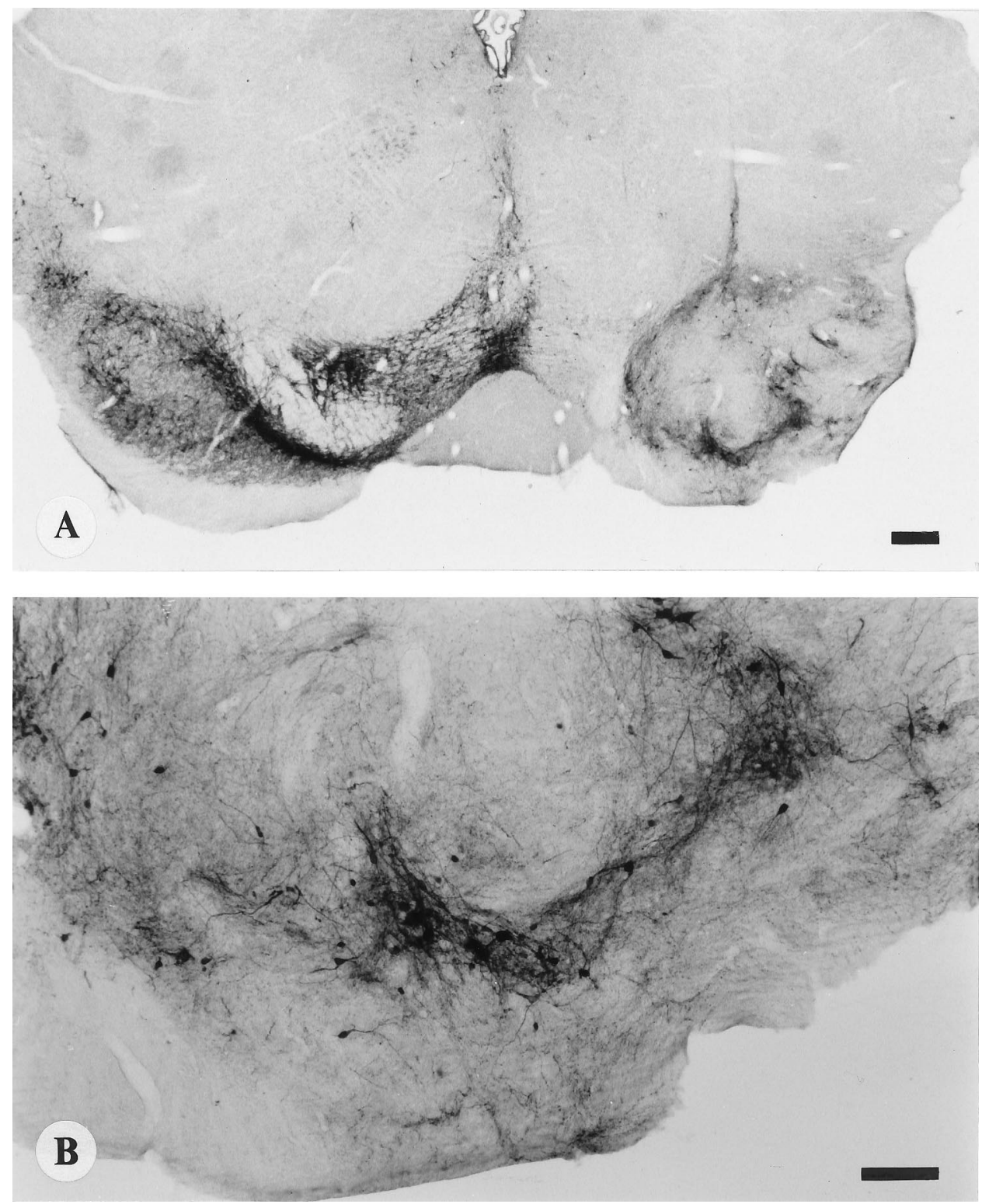

Figure 2. $A$, TH-immunostained coronal section of the VM of a rat with a right 6-OHDA lesion of the nigrostriatal pathway and an intranigral dopaminergic graft; $B$, high-power view of the intranigral graft in $A$. Numerous TH-positive neurons are present in clusters forming dense networks of fibers penetrating the host striatum. Scale bars: $A$, $300 \mu \mathrm{m} ; B: 100 \mu \mathrm{m}$. received double grafts. In some animals, labeled cells were also present in the needle tract of the intranigral graft (Fig. 8).

\section{Control double graft}

Rats with intrastriatal cortical grafts and intranigral VM grafts were found to have no $\mathrm{TH}$ immunoreactivity in the grafted site (Fig. 9). The appearance of the intranigral VM grafts was comparable to the VM transplants in the intranigral group. THimmunoreactive cells were found to be clustered in the periphery of the graft, with fewer cells observed in the center. Numerous TH-immunoreactive fibers were seen within the graft and its periphery. No fibers could be traced within the internal capsule or the MFB or reaching the striatal complex (Fig. 9).

\section{Rotational behavior}

Animals with double grafts had complete restoration of amphetamine-induced rotational behavior 6 weeks after grafting. Furthermore, four of six rats receiving double grafts rotated contraversively to the lesion. This contraversive rotation was not statistically significant. Animals with intrastriatal grafts alone also improved their rotational scores; however, they did not achieve the more complete compensation observed in rats with double grafts. Animals with nondopaminergic (cortex) intrastriatal grafts and dopaminergic intranigral grafts (double control grafts) had virtually identical rotational scores compared with animals with intranigral grafts alone. These two groups did not improve their rotational scores, and in some cases the amphetamine-induced ipsilateral rotation was higher than it was preoperatively. The difference in the rotational scores between the rats with double grafts and either the intrastriatal or intranigral graft groups was statistically significant (Fig. 10).

\section{DISCUSSION}

The ability of long axonal outgrowth along myelinated pathways in animal models of neural transplantation has been observed only when bridge techniques were used (Dunnett et al., 1989; Zhou and Chiang, 1995; Brecknell et al., 1996) or when transplants were placed in the immature CNS (Floeter and Jones, 1984; Stanfield and O'Leary, 1985; Lund et al., 1990). Neonatal rats were also 

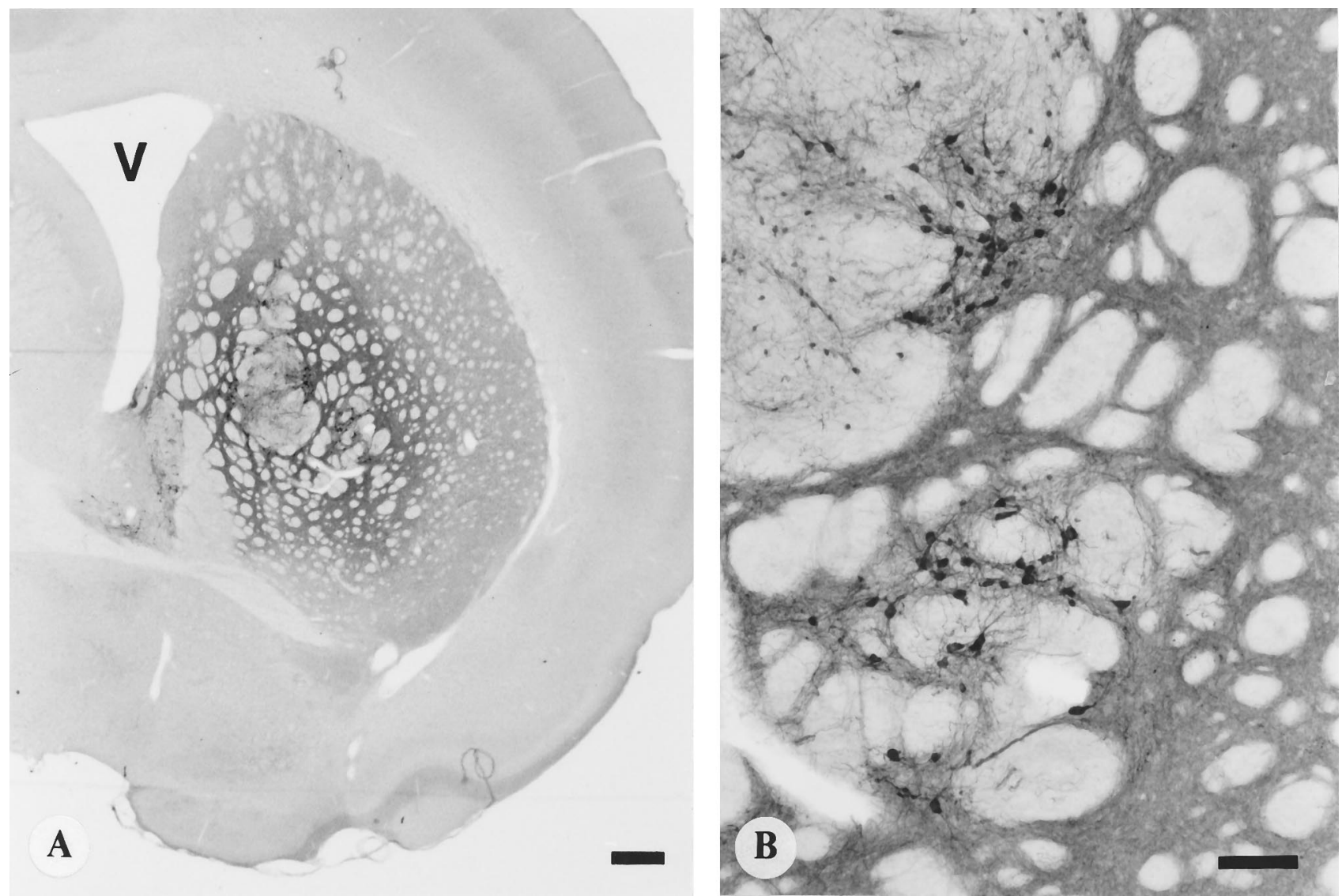

Figure 3. A, Coronal section of the dopamine-depleted striatum immunostained for TH. Two graft deposits are present. A halo of TH-immunoreactive fibers penetrating the host striatum can be clearly seen surrounding the graft. $B$, High-power view of the graft showing numerous TH-positive neurons and dense TH immunostaining surrounding the graft. $V$, Lateral ventricle. Scale bars: $A, 400 \mu \mathrm{m} ; B: 100 \mu \mathrm{m}$.

used to demonstrate TH-immunoreactive axonal outgrowth from a nigral graft placed in the VM along myelinated pathways to reinnervate the ipsilateral striatum (Nikkhah et al., 1995a,b). The present study demonstrates for the first time, however, that simultaneous intrastriatal and intranigral nigral grafts reconstruct the dopaminergic nigrostriatal pathway in the adult CNS. These results provide evidence that $\mathrm{TH}$-immunoreactive axons arising from dopaminergic neurons transplanted homotopically into the VM growing over long distances along the internal capsule and the MFB reach and reinnervate the ipsilateral striatum that has also received a dopaminergic transplant.

\section{Single versus double grafts}

Numerous studies have demonstrated reinnervation of the dopamine-depleted striatum by ectopically placed nigral fetal transplants into the striatum (Björklund et al., 1980; Bolam et al., 1987; Dunnett and Björklund, 1987; Mendez et al., 1991); however, no evidence of axonal growth along the striatonigral pathway has been observed. The graft-derived $\mathrm{TH}$-immunoreactive innervation seems to be confined to the striatum, and no afferent host-graft connections have been demonstrated (Freund et al., 1985; Mendez et al., 1991). This lack of host-graft connections may impair graft regulation by the host. Nigral transplants, homotopically placed into the VM, have also been attempted (Nikkhah et al., 1994b; Olsson et al., 1995). Although graft integration into the host VM was demonstrated, no evidence of axonal outgrowth along the nigrostriatal pathway was observed (Nikkhah et al., 1994b). In the present study, animals receiving either an intrastriatal or intranigral transplant alone did not show any axonal growth along the nigrostriatal pathway, thus confirming those previous observations.

Although several strategies have been used in an attempt to reconstruct the nigrostriatal pathway in the adult CNS, such as using bridge grafts, xenografts, and ibotenic and kainic acid lesions along the nigrostriatal pathway (Dunnett et al., 1989; Wictorin et al., 1990; 1992; Zhou and Chiang, 1995; Brecknell et al., 1996), this is the first time that fetal nigral transplants placed simultaneously in the striatum and VM have shown the ability to reconstruct the nigrostriatal pathway. This study suggests that the intrastriatal graft may promote growth and guidance to direct axonal growth from the intranigral transplant along the internal capsule and the MFB to the appropriate target (the striatum). The FG retrograde tracing experiment confirms that VM graft fibers reach the ipsilateral striatum. It is unlikely that this pathway reconstruction is attributable to sprouting of surviving axons after the lesion, because no TH-immunoreactive fibers were observed in the MFB, internal capsule, or ipsilateral striatum in animals receiving a 6-OHDA lesion alone. Fetal nigral neurons seem to have the ability for long-distance axonal growth when implanted into a permissive environment such as the neonatal rat (SnyderKeller et al., 1989; Herman et al., 1991). Furthermore, reconstruction of the nigrostriatal pathway by nigral grafts implanted into the VM of neonatal rats has been demonstrated (Nikkhah et al., $1995 \mathrm{a}, \mathrm{b})$. It is possible that the dopaminergic intrastriatal transplant provides the necessary factors to promote growth and guid- 

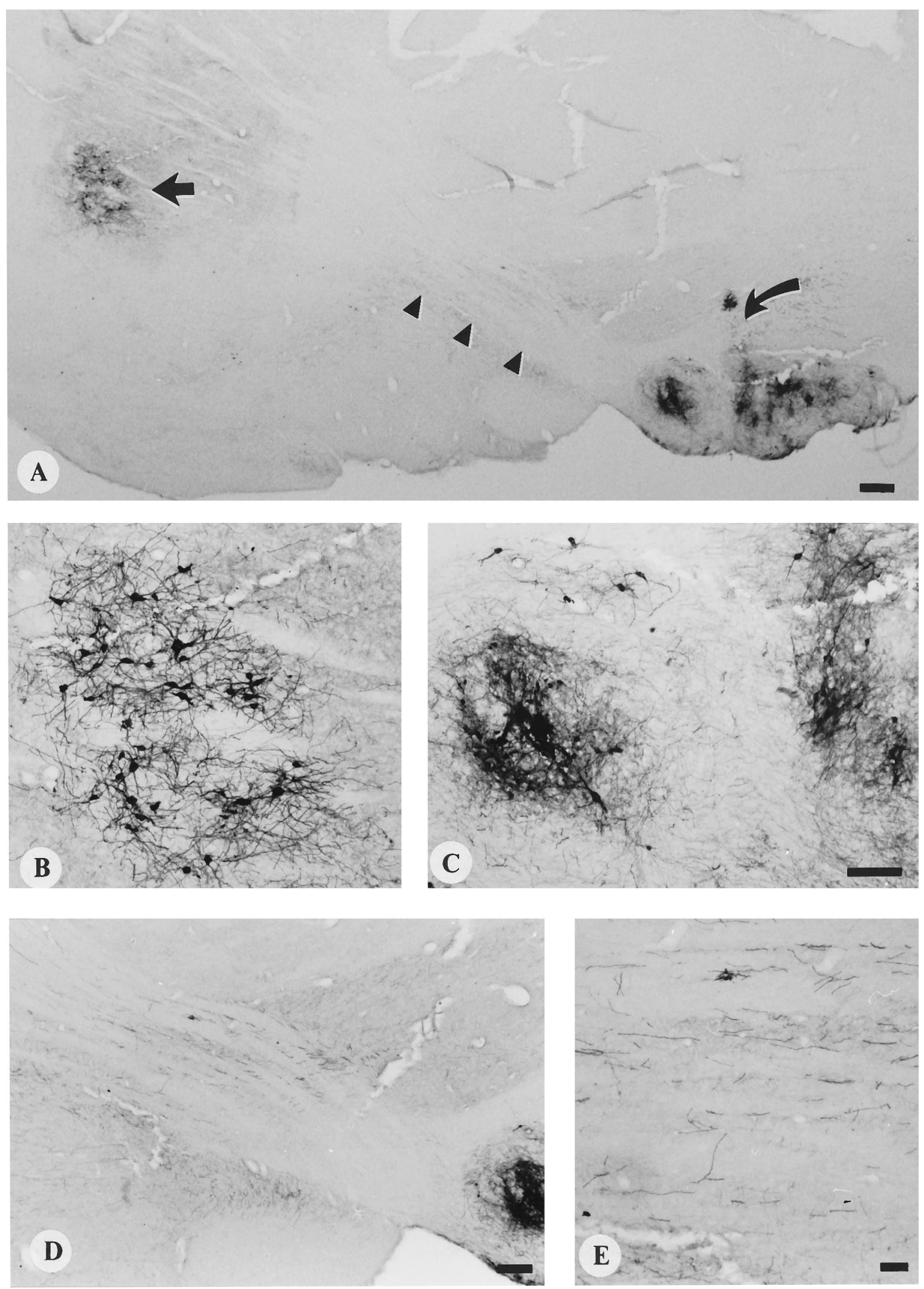

Figure 4. A, Representative parasagittal section of a rat implanted with simultaneous intrastriatal and intranigral dopaminergic grafts. Dense TH-immunoreactive areas are seen in the VM and striatum: intranigral graft (curved arrow), intrastriatal graft (straight arrow), and TH-immunoreactive axons growing along the internal capsule (arrowheads). $B$, High-power view of the intrastriatal transplant. $C$, High-power view of the intranigral transplant $D$, High-power view of TH-immunoreactive axons traveling within the internal capsule. $E$, Close-up of $D$ showing the direction of TH-positive axons. Scale bars: $A, 300 \mu \mathrm{m} ; B, 75 \mu \mathrm{m} ; C, 75 \mu \mathrm{m} ; D, 250 \mu \mathrm{m} ; E, 100 \mu \mathrm{m}$. 

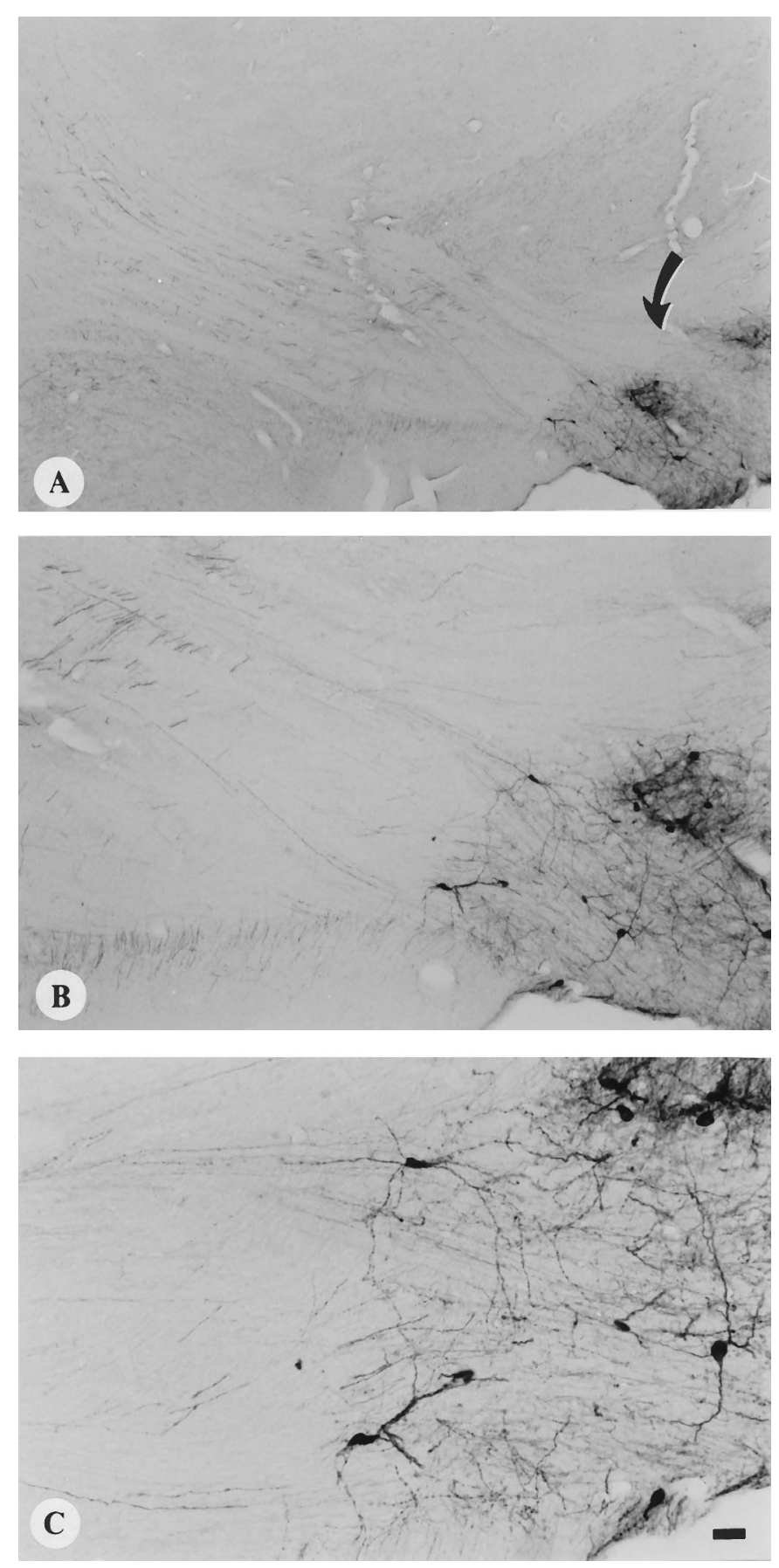

Figure 5. Parasagittal section of an intranigral graft in an animal with double grafts. $A$, TH-immunoreactive axons can be seen arising from the dense cluster of neurons (curved arrow) in the intranigral graft. $B$, Highpower view of $A$ showing axons growing rostrally along the internal capsule and the MFB. $C$, Close-up of intranigral graft showing a cluster of TH-positive neurons and fibers growing toward the MFB. Scale bars: $A$, $250 \mu \mathrm{m} ; B, 500 \mu \mathrm{m} ; C, 1000 \mu \mathrm{m}$.

ance of TH-immunoreactive axons originating in the intranigral graft. This effect seems to be specific to dopaminergic tissue, because no fiber outgrowth from the intranigral grafts was observed in control rats that received a nondopaminergic (cortex) intrastriatal graft. Previous studies have demonstrated that striatal fetal tissue can stimulate the outgrowth of dopaminergic fibers in vitro (Prochiantz et al., 1979; Denis-Donini et al., 1983). It is conceivable that fetal nigral tissue may have a similar effect. A number of factors have been proposed as being capable of stimulating axonal growth along myelinated pathways in the immature CNS (for reviews, see Edelman and Crossin, 1991; Takeichi, 1991). It seems that developing neural tissue provides a permissive environment for axonal outgrowth by maintaining low expression of certain growth-inhibiting factors such as extracellular matrix molecules (chondroitin-6-sulfate proteglycan and cytotactin/tenascin) and higher expression of growth-promoting factors such as laminin, collagen, and fibronectin (McKeon et al., 1991). We postulate that simultaneous fetal nigral grafts placed ectopically in the striatum and homotopically in the VM may encourage axonal growth and guidance. This effect may result from a tropic effect of the intrastriatal graft on the VM tissue of the intranigral graft, which presumably lacks receptors for growth-inhibiting factors produced by the mature CNS.

\section{Functional effects}

When amphetamine-induced turning behavior was analyzed in rats with double and single grafts 6 weeks after transplantation, it was clear that animals receiving simultaneous intrastriatal and intranigral grafts had total restoration of motor symmetry. Furthermore, we observed an overcompensation with contralateral rotation instead of the ipsilateral rotation that is characteristic of the amphetamine effect. This effect has been observed before in fetal nigral transplantation in neonatal (Herman et al., 1991) and adult (Herman et al., 1985) rats. Although the mechanism of this overcompensation phenomenon is not clear, it has been proposed that the amphetamine-dependent dopamine release is higher in the transplant side than in the contralateral intact side (Forni et al., 1989). In contrast, the turning behavior recovery in animals transplanted with a single intrastriatal graft, although significant, was not complete, and no overcompensation was observed. In animals receiving an intranigral graft alone, no rotational compensation was observed, and in some animals the ipsilateral rotations were higher than they were preoperatively. Virtually identical rotational behavior was observed in animals receiving a nondopaminergic (cortex) intrastriatal graft and a dopaminergic intranigral graft (double control grafts). This lack of rotational compensation in intranigral grafts, observed previously (Nikkhah et al., 1994a), seems to be related to the lack of dopamine release by the intranigral graft in the striatum. Intranigral grafts, however, compensate for rotational asymmetry caused by injection of SKF 38393 (D1 agonist), apomorphine (mixed D1 and D2 agonist), and quinpirole (D2 agonist) (Nikkhah et al., 1994a). This functional recovery has been postulated to occur by the restoration of dopaminergic function by the graft in the substantia nigra itself, which is considered one of the two principal striatal output structures. In a recent study, Olsson et al. (1995) reported improvement in forelimb akinesia as assessed by a new stepping test in rats receiving simultaneous intrastriatal and intranigral dopaminergic grafts. Additional experiments currently underway in our laboratory are looking at turning behavior induced by D1 and D2 agonists, as well as more complex behavioral tests such as skilled forelimb use, sensorimotor orientation, and disengage behavior in animals receiving double grafts.

The dopaminergic reinnervation of the striatum in animals receiving double grafts was qualitatively greater than in rats with intrastriatal grafts only. This greater striatal reinnervation may explain the rapid restoration and in some cases overcompensation of rotational behavior in animals with double grafts. Previous studies have shown that the degree of turning behavior induced by 

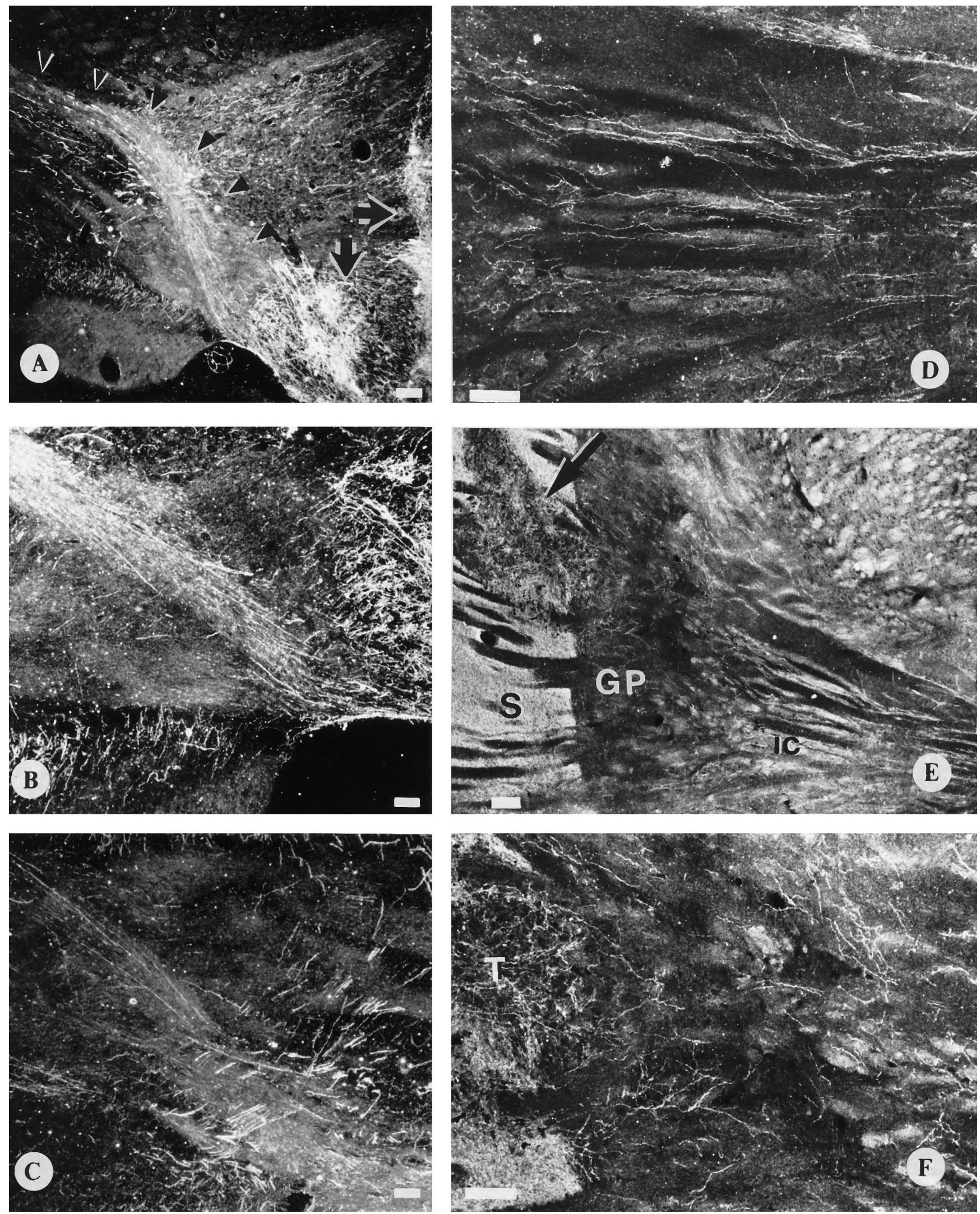

Figure 6. Dark-field microphotographs of a rat implanted with double grafts. $A$, Intranigral TH-immunoreactive graft (arrows). A dense bundle of axons can be seen growing toward the internal capsule and the MFB (arrowheads). B, High-power view of $A$ showing TH-immunoreactive fibers coming from the graft. $C$, Graft-derived fibers entering the internal capsule. $D$, Numerous TH-immunoreactive fibers growing along the internal capsule. $E$, Ipsilateral striatum $(S)$ containing a nigral graft (arrow). The graft is located in the striatal/pallidal border. GP, Pallidum; IC, internal capsule. $F$, Close-up of the transplant $(T)$. Numerous fibers are seen growing into the pallidum. Scale bars: $A, 150 \mu \mathrm{m} ; B, 500 \mu \mathrm{m} ; C, 500 \mu \mathrm{m} ; D, 100 \mu \mathrm{m} ; E, 75 \mu \mathrm{m} ; F, 100 \mu \mathrm{m}$. 

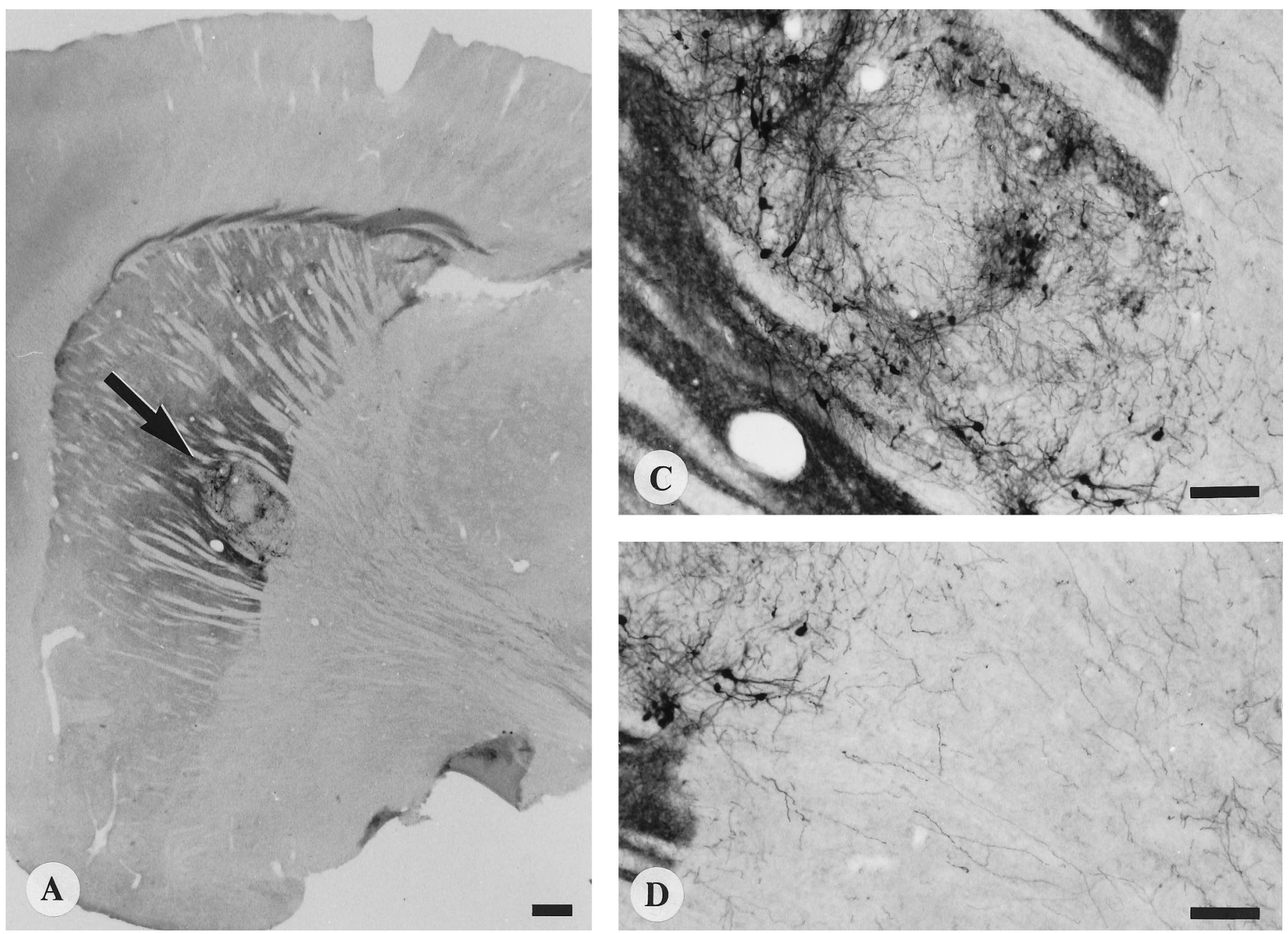

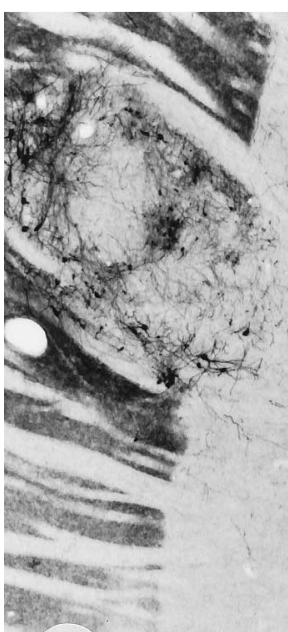

B

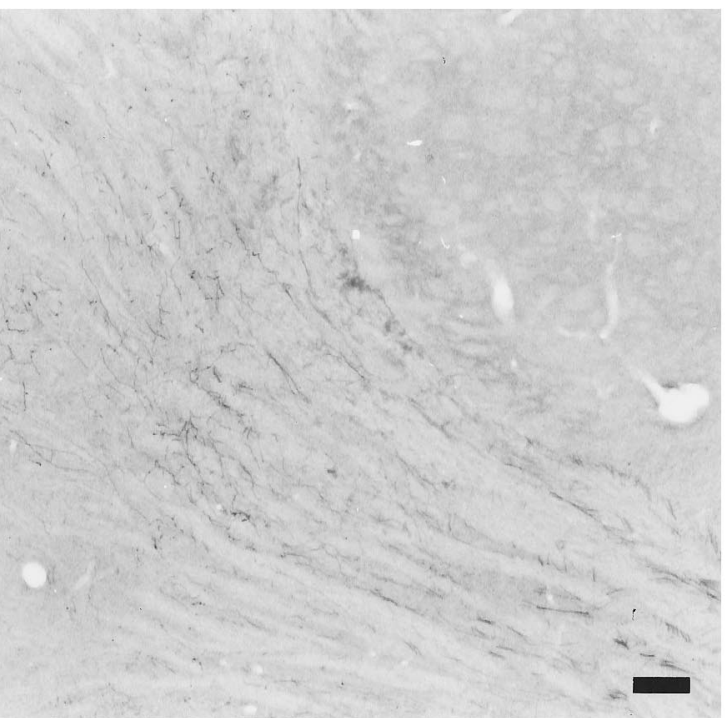

Figure 7. Bright-field microphotographs showing the intrastriatal dopaminergic graft of an animal transplanted with double grafts. $A$, THimmunoreactive graft (arrow) located in the striatal/pallidal border. A dense halo of TH immunoreactivity surrounds the transplant. $B$, High-power view of $A$ showing TH-immunoreactive fibers from the intranigral graft growing along the internal capsule and reaching the striatum. $C$, Close-up of the intrastriatal graft. $D$, Graft/pallidum border showing TH-immunoreactive fibers transversing the pallidum. $E$, High-power view of the internal capsule containing numerous TH-immunoreactive fibers. Scale bars: $A, 400 \mu \mathrm{m} ; B, 200 \mu \mathrm{m} ; C, 100 \mu \mathrm{m} ; D, 100 \mu \mathrm{m} ; E, 100 \mu \mathrm{m}$. 

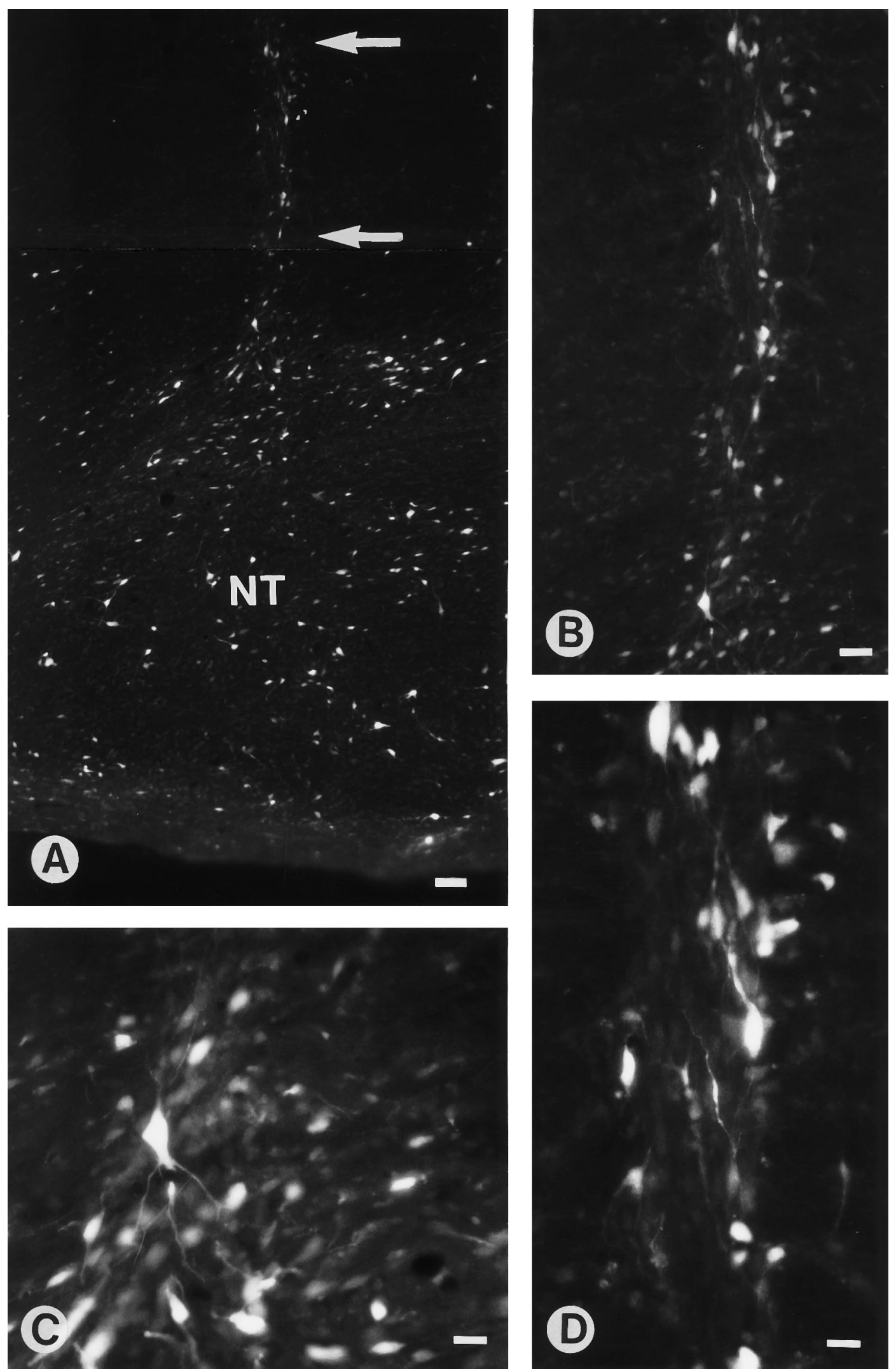

Figure 8. Fluorescence microphotographs of representative parasagittal sections of intranigral-grafted neurons retrogradely labeled from an FG injection into the striatum. $A$, Retrogradely labeled neurons within the intranigral graft $(N T)$. B, Retrogradely labeled neurons within the needle tract (arrows in $A$ ). $C$, High-power view of labeled neurons in the intranigral graft. $D$, High-power view of labeled neurons in the needle tract. Scale bars: $A, 250 \mu \mathrm{m} ; B$, $500 \mu \mathrm{m} ; C, 1000 \mu \mathrm{m}$. 

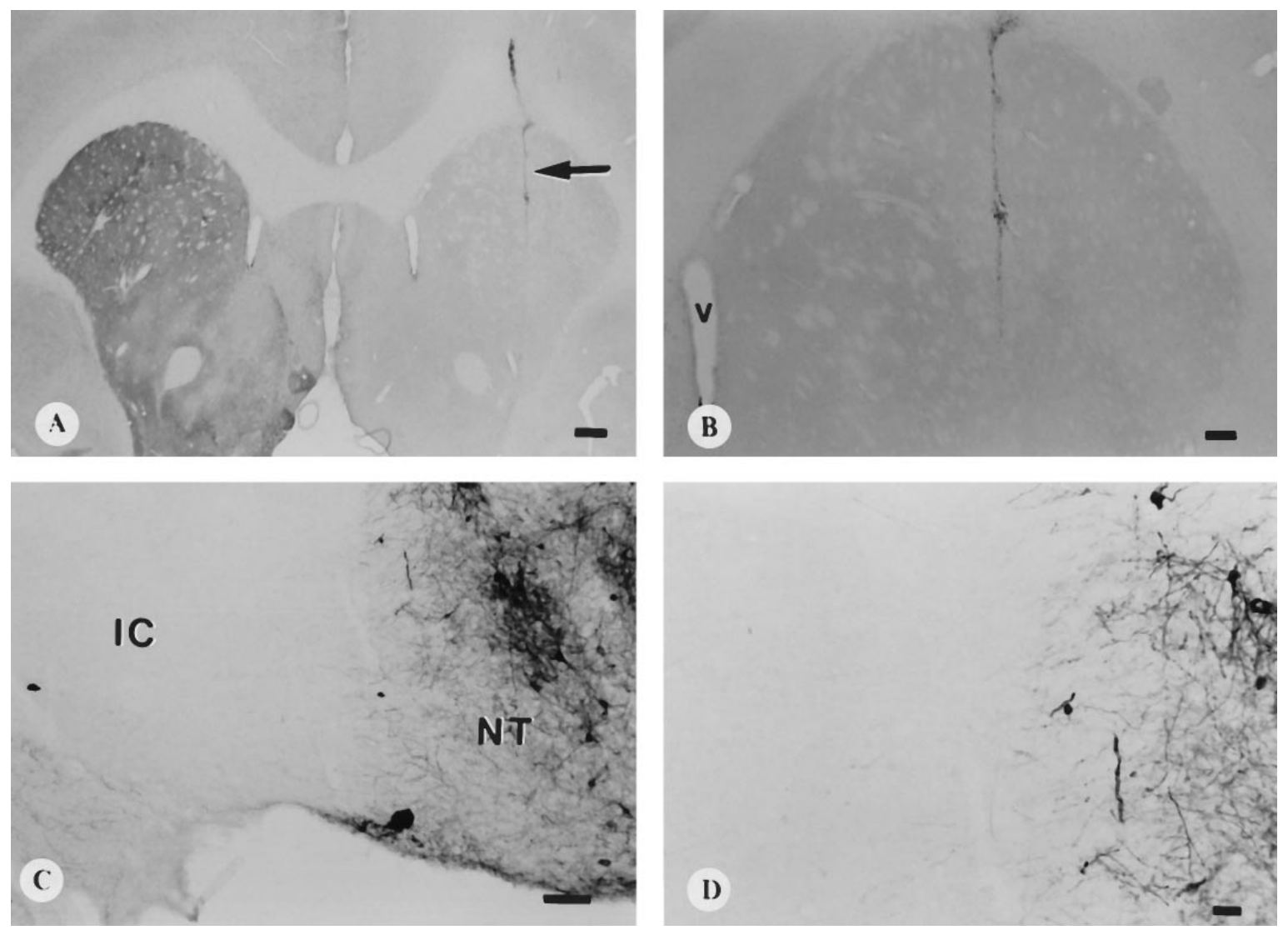

Figure 9. Representative sections of TH immunostaining of the brain of a 6-OHDA lesioned rat grafted with a nondopaminergic (cortex) intrastriatal graft and a dopaminergic intranigral graft. $A$, Coronal section of the striata immunostained for TH. Note the lack of TH immunostaining in the striatum ipsilateral to the lesion and the needle track of the nondopaminergic graft (arrow). B, High-power view of the transplanted striatum. No TH immunoreactivity can be seen surrounding the nondopaminergic transplant. The needle track can be clearly seen containing macrophages that have bound secondary antibody. $V$, Lateral ventricle. $C$, Sagittal view of the intranigral graft $(N T)$ showing numerous immunoreactive structures. In contrast to Figure 5 , no fibers can be seen entering the internal capsule $(I C)$. $D$, High-power view of the border between the intranigral graft and internal capsule showing the lack of fiber outgrowth across the border. Scale bars: $A, 500 \mu \mathrm{m} ; B, 250 \mu \mathrm{m} ; C, 200 \mu \mathrm{m} ; D, 75 \mu \mathrm{m}$.

amphetamine was related directly to the extent of dopaminergic reinnervation in adult and neonatal hosts (Björklund and Stenevi, 1979; Björklund et al., 1980; Carder et al., 1987); however, the degree of contribution of the intranigral graft to striatal reinnervation is not known. To answer this question, we are currently conducting tracing experiments to differentiate between the intrastriatal and intranigral graft contribution to the reinnervation of the dopamine-depleted striatum. Experiments along the same lines are also being conducted to determine whether a reciprocal striatonigral innervation is present.

\section{Concluding remarks}

The present study demonstrates, for the first time, the ability of simultaneous intranigral and intrastriatal dopaminergic transplants to reestablish the nigrostriatal pathway. These double grafts not only seem to achieve a greater striatal dopaminergic reinnervation than the standard intrastriatal graft, but they also result in a faster rotational recovery to amphetamine challenge. These results strongly suggest that embryonic VM tissue implanted in a heterotopic location (striatum) can promote dopaminergic axonal growth and guidance for grafted cells implanted homotopically in the distant VM. The more extensive functional effects observed in animals receiving double grafts suggests the possibility that reconstruction of the nigrostriatal pathway may not only lead to a greater striatal reinnervation but may also

\section{Amphetamine Induced Turning Behaviour}

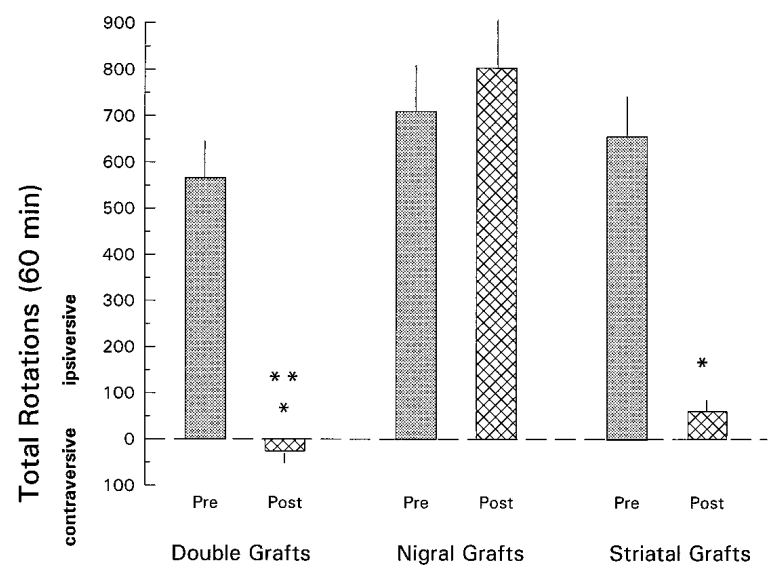

Figure 10. Rotational behavior of rats bearing unilateral 6-OHDA lesions of the nigrostriatal dopaminergic pathway after amphetamine challenge $(5 \mathrm{mg} / \mathrm{kg}$, i.p.) before (stipled bars) and 6 weeks after (cross-hatched bars) micrografting of fetal dopaminergic cells into either the striatum or nigra (single grafts) and micrografting into both the striatum and nigra (double grafts). Each bar represents the mean \pm SEM total rotations in 60 min; $n=4-6$ in each group; ${ }^{*} p<0.05$ compared with pregrafting; ${ }^{* *} p<$ 0.05 compared with intrastriatal and intranigral grafts. 
reestablish some of the nigrostriatal control mechanisms found in the intact system that cannot be recreated by ectopically placed transplants. If this is the case, double grafts may provide an answer to the issue of graft control and regulation, which is one of the most serious obstacles that has plagued experimental and clinical neural transplantation for Parkinson's disease.

\section{REFERENCES}

Björklund A, Stenevi U (1979) Reconstruction of the nigrostriatal dopamine pathway by intracerebral nigral transplants. Brain Res 177:555-560.

Björklund A, Schmidt RH, Stenevi U (1980) Functional reinnervation of the neostriatum in the adult rat by use of intraparenchymal grafting from the substantia nigra. Cell Tissue Res 212:39-45.

Bolam JP, Freund TF, Björklund A, Dunnett SB, Smith AD (1987) Synaptic input and local output of dopaminergic neurons in grafts that functionally reinnervate the host neostriatum. Exp Brain Res 68:131-146.

Brecknell JE, Haque NSK, Du J-S, Muir EM, Fidler PS, Hlavin M-L, Fawcett JW, Dunnett SB (1996) Functional and anatomical reconstruction of the 6-hydroxydopamine lesioned nigrostriatal system of the adult rat. Neuroscience 71:913-925.

Carder RK, Snyder-Keller AM, Lund RD (1987) Amphetamine- and stress-induced turning after nigral transplants in neonatally dopaminedepleted rats. Dev Brain Res 33:315-318.

Clarke DJ, Brundin P, Strecker RE, Nilsson OG, Björklund A, Lindvall O (1988) Human fetal dopamine neurons grafted in a rat model of Parkinson's disease: ultrastructure evidence for synapse formation using tyrosine hydroxylase immunocytochemistry. Exp Brain Res 73:115-126.

Denis-Donini S, Glowinski J, Prochiantz A (1983) Specific influence of striatal target neurons on the in vitro outgrowth of mesencephalic dopaminergic neurites: a morphological qualitative study. Neuroscience 3:2292-2299.

Doucet G, Murata Y, Brundin P, Bosler O, Mons N, Geffard M, Ouimet CC, Björklund A (1989) Host afferents into intrastriatal transplants of fetal ventral mesencephalon. Exp Neurol 106:1-19.

Dunnett SB, Björklund A (1987) Mechanisms of function of neural grafts in the adult mammalian brain. J Exp Biol 132:265-289.

Dunnett SB, Rogers DC, Richards S-J (1989) Nigrostriatal reconstruction after 6-ODHA lesion in rats: combination of dopamine-rich nigral grafts and nigrostriatal "bridge" grafts. Exp Brain Res 75:523-535.

Edelman GM, Crossin KL (1991) Cell adhesion molecules: implications for a molecular histology. Annu Rev Biochem 60:155-190.

Floeter MK, Jones EJ (1984) Connections made by transplants to the cerebral cortex of rat brains damaged in utero. J Neurosci 4:141-150.

Forni C, Brundin P, Stricker EM, El Ganouni S, Björklund A, Nieoullon A (1989) Time-course of recovery of dopamine neuron activity during reinnervation of the denervated striatum by fetal mesencephalic grafts as assessed by in vivo voltammetry. Exp Brain Res 76:75-87.

Freund TF, Bolam JP, Björklund A, Stenevi U, Dunnett SB, Powell JF, Smith AD (1985) Efferent synaptic connections of grafted dopaminergic neurons reinnervating the host neostriatum: a tyrosine hydroxylase immunocytochemical study. J Neurosci 5:603-616.

Herman JP, Choulli K, Le Moal M (1985) Hyper-reactivity to amphetamine in rats with dopaminergic grafts. Exp Brain Res 60:521-526.

Herman JP, Abrous DN, Le MM (1991) Anatomical and behavioral comparison of unilateral dopamine-rich grafts implanted into the striatum of neonatal and adult rats. Neuroscience 40:465-475.

Lund RD, Radel JD, Hankin MH, Klassen H, Coffey PJ, Rawlins JNP (1990) Developmental and functional integrations of retinal transplants with host rat brains. In: Brain repair (Björklund A, Aguayo AJ, Ottoson D, eds), pp 327-340. London: McMillan.

McKeon RJ, Schreiber RC, Rudge JS, Silver J (1991) Reduction of neurite outgrowth in a model of glial scarring following CNS injury is correlated with expression of inhibitory molecules on reactive astrocytes. J Neurosci 11:3398-3411.
Mendez I, Elisevich K, Flumerfelt B (1991) Dopaminergic innervation of substance P-containing striatal neurons by fetal nigral grafts: an ultrastructural double-labeling immunocytochemical study. J Comp Neurol 308:66-78.

Nikkhah G, Bentlage C, Cunningham MG, Björklund A (1994a) Intranigral fetal dopamine grafts induce behavioral compensation in the rat Parkinson model. J Neurosci 14:3449-3461.

Nikkhah G, Cunningham MG, Jödicke A, Knappe U, Björklund A (1994b) Improved graft survival and striatal reinnervation by microtransplantation of fetal nigral cell suspensions in the rat Parkinson model. Brain Res 633:133-143.

Nikkhah G, Olsson M, Eberhard J, Bentlage C, Cunningham MG, Björklund A (1994c) A microtransplantation approach for cell suspension grafting in the rat Parkinson model: a detailed account of the methodology. Neurology 63:57-72.

Nikkhah G, Cunningham MG, Cenci MA, McKay RD, Björklund A (1995a) Dopaminergic microtransplants into the substantia nigra of neonatal rats with bilateral 6-OHDA lesions. I. Evidence for anatomical reconstruction of the nigrostriatal pathway. J Neurosci 15:3548-3561.

Nikkhah G, Cunningham MG, McKay R, Björklund A (1995b) Dopaminergic microtransplants into the substantia nigra of neonatal rats with bilateral 6-OHDA lesions. II. Transplant-induced behavioral recovery. J Neurosci 15:3562-3570.

Olsson M, Nikkhah G, Bentlage C, Björklund A (1995) Forelimb akinesia in the rat Parkinson model: differential effects of dopamine agonists and nigral transplants as assessed by a new stepping test. J Neurosci 15:3863-3875.

Prochiantz A, DiPorzio U, Kato A, Berger B, Glowinski J (1979) In vitro maturation of mesencephalic dopaminergic neurons from mouse embryos is enhanced in presence of their striatal target cells. Proc Natl Acad Sci USA 76:5387-5391.

Schnell L, Schwab ME (1990) Axonal regeneration in the rat spinal cord produced an antibody against myelin-associated neurite growth inhibitors. Nature 343:269-272.

Schwab ME (1990) Myelin-associated inhibitors of neurite growth and regeneration in the CNS. Trends Neurosci 13:452-455.

Schwab ME, Kapfhammer JP, Bandtlow CE (1993) Inhibitors of neurite growth. Annu Rev Neurosci 16:565-595.

Snyder-Keller AM, Carder RK, Lund RD (1989) Development of dopamine innervation and turning behavior in dopamine-depleted infant rats receiving unilateral nigral transplants. Neuroscience 30:779-794.

Stanfield BB, O'Leary DDM (1985) Fetal occipital cortical neurones transplanted to the rostral cortex can extend and maintain a pyramidal tract axon. Nature 313:135-137.

Takeichi M (1991) Cadherin cell adhesion receptors as a morphogenetic regulator. Science 251:1451-1455.

Wictorin K, Ouimet CC, Björklund A (1989a) Intrinsic organization and connectivity of intrastriatal striatal transplants in rats as revealed by DARPP-32 immunohistochemistry: specificity of connections with the lesioned host brain. Eur J Neurosci 1:690-701.

Wictorin K, Simberly RB, Isacson O, Swanson LW, Björklund A (1989b) Connectivity of striatal grafts implanted into the ibotenic acid-lesioned striatum. III. Efferent projecting graft neurons and their relation to host afferents within the grafts. Neuroscience 30:313-330.

Wictorin K, Brundin P, Gustavii B, Lindvall O, Björklund A (1990) Reformation of long axon pathways in adult rat central nervous system by human forebrain neuroblasts. Nature 347:556-558.

Wictorin K, Brundin P, Sauer H, Lindvall O, Björklund A (1992) Long distance directed axonal growth from human dopaminergic mesencephalic neuroblasts implanted along the nigrostriatal pathway in 6-hydroxydopamine lesioned adult rats. J Comp Neurol 323:475-494.

Zhou FC, Chiang YH (1995) Excitochemical-induced trophic bridging directs axonal growth of transplanted neurons to distal target. Cell Transplant 4:103-112. 